\section{$\longrightarrow$ TACKLING UNDECLARED WORK IN THE EUROPEAN UNION}

\section{Colin C. Williams and SARA NAdiN*}

\section{Introduction}

At the 2003 Lisbon Summit of the European Council, tackling undeclared work was named as one of the top ten priorities for action with regard to employment reform (European Commission 2003a, 2003b and 2003c). With the declining employment participation rates in Europe, the European Commission recognised that the conventional approach that sought to deter engagement in undeclared work needed to be transcended. Instead, a new facilitating formalisation approach was advocated that seeks to move undeclared work into the declared realm (European Commission 2007). This paper evaluates the degree to which this has been adopted by European national governments.

To this end, the first section will briefly review the extent and nature of undeclared work in Europe, while the second section will examine the various possible policy approaches available for tackling undeclared work. Revealing that the European Commission has recently called for a new approach that seeks to legitimise undeclared work rather than simply deter it, the third section then reports an evaluation of the degree to which European national governments have adopted this policy approach. Reporting a 2010 survey of 104 senior stakeholders from government departments, trade unions and employer organisations in 31 European countries, and 24 follow-up in-depth interviews, this section displays that although there is a move towards adopting poli-

* University of Sheffield. The research in this paper results from the European Commission funding a feasibility study on establishing a European platform for cooperation between labour inspectorates, and other relevant monitoring and enforcement bodies, to prevent and fight undeclared work (VT/2009/049). The authors would like to thank the European Commission for funding this study. The usual disclaimers apply. cy measures to legitimise undeclared work, deterring undeclared work remains the principal approach in most nations. The fourth and final section will then draw some conclusions and discuss the implications of intransigence on the part of European national governments.

Before commencing, however, undeclared work needs to be defined. Despite some 45 different nouns and 10 adjectives used to denote this realm, including the 'cash-in-hand', 'shadow', 'informal', 'black' and 'underground' economy/sector/work (Williams 2004), a strong consensus exists that undeclared work should be defined by what is absent from, or insufficient about it compared with declared work. The widelyheld view is that the only absence from, or insufficiency about, undeclared work is that this remunerated production and/or sale of licit goods and services is not declared to the authorities for tax, social security and/or labour law purposes when it should be declared (European Commission 1998 and 2007; OECD 2002). If other absences or insufficiencies exist, then the definition of undeclared work does not apply. If the goods and/or services are illegal (e.g. drug-trafficking), for example, then this constitutes 'criminal' activity. If the activity is not remunerated, on the other hand, it is not part of the undeclared economy, but belongs to the unpaid sphere.

\section{Extent and nature of undeclared work in Europe}

For many decades, a 'size matters' perspective dominated the study of undeclared work. Scholars concentrated on measuring the magnitude of this realm using indirect measurement methods (Friedman et al. 2000; Schneider et al. 2011). Little attention was paid to evaluating the nature of undeclared work. Nevertheless, a number of small-scale direct surveys have begun to do so (Neef 2002; Round et al. 2008; Williams 2006). These surveys have challenged the conventional dominant depiction of undeclared work as low-paid waged employment conducted under degrading 'sweatshop-like' conditions (Davis 2006; Sassen 1996), which conventionally led governments to view this sphere as something to be deterred. 
On the one hand, a range of additional types of undeclared waged employment have been identified. Not only has well-paid undeclared waged work been recognised (Williams and Windebank 2011), but it has been also shown that besides 'undeclared' jobs wholly hidden from the state for tax, social security and labour law purposes, there are also 'under-declared' formal jobs where declared employees receive two wages from their declared employer, one declared and one undeclared 'envelope wage' (Karpuskiene 2007; Williams 2007; Woolfson 2007).

On the other hand, it has been shown that a lot of undeclared work in many places is conducted on an own-account or self-employed basis (Round et al. 2008; Williams 2005). Until recently, most of this undeclared self-employment was assumed to be conducted under market-like relations for profit-motivated purposes. However, in some populations it has been identified how such own-account undeclared work is commonly undertaken for closer social relations such as kin, neighbours, friends and acquaintances, for the purposes of redistribution and helping out, rather than purely for financial gain (Persson and Malmer 2006; Williams 2004).

Until recently, such findings regarding the nature of undeclared work derived almost entirely from smallscale studies of particular populations. In 2007, however, an extensive survey of undeclared work involving 26,659 face-to-face interviews in 27 European countries was conducted as part of wave 67.3 of Eurobarometer (TNS Infratest et al. 2006; Williams and Windebank 2011). It finds that just under one in ten ( 9 percent) of the surveyed population participated in either undeclared or under-declared work in the 12 months prior to interview, of which 4 percent engaged solely in undeclared work, a further 4 percent solely in under-declared work and 1 percent in both undeclared and under-declared work.

Examining the nature of the wholly undeclared work, just 22 percent was waged employment and 78 percent undertaken on a self-employed basis; with 57 percent being conducted on a self-employed basis for closer social relations and 21 percent on a self-employed basis for other private individuals, households and businesses.

Analysing under-declared work, meanwhile, 1 in 20 (5 percent) of all declared employees received envelope wages from their formal employer in the previous year amounting on average to over two-fifths (43 per- cent) of their gross total wage. Of these employees, 29 percent received such payments for their regular work, 27 percent for extra work or overtime and 36 percent for both their regular and overtime work. Extrapolating to the EU as a whole, this intimates that some 11 million of the 210 million employees in the EU might be in receipt of envelope wages: some 3 million for their regular work, 3 million for overtime or extra work and 4 million for both their regular and overtime work. This re-reading of the nature of work in the undeclared economy has significant implications for how undeclared work is tackled.

\section{Policy approaches towards undeclared work}

Tackling undeclared work has been traditionally dominated by a deterrence approach that seeks to eradicate it. Reading undeclared workers as 'rational economic actors' who will evade tax so long as the pay-off from evading is greater than the expected cost of being caught and punished (Allingham and Sandmo 1972), the goal has been to deter it by changing the cost/benefit ratio confronting those engaged or thinking about participating in such endeavours (e.g. Hasseldine and Li 1999; Richardson and Sawyer 2001). This is achieved by increasing the actual and perceived risks and costs associated with participation by raising the perceived or actual likelihood of detection andraising the penalties and sanctions for those caught.

Recently, nevertheless, the validity of this approach has been questioned for three reasons. Firstly, it has been argued that increasing the probability of detection and/or increasing penalties can produce the opposite behaviour to that sought (Murphy 2005; Schneider et al. 2011). Secondly, and given that undeclared self-employment is often a seedbed for entrepreneurship and enterprise development (Small Business Council 2004; Williams 2006), it has been recognised that if national governments seek to eradicate it, their policies onundeclared work may deter precisely the enterprise and entrepreneurship that their enterprise culture policies are seeking to foster. Similarly, given that much undeclared work is embedded in relations of familial and community solidarity, deterring such endeavour will also result in governments suppressing precisely the mutual aid that their policies on promoting active citizenship are wishing to foster (Williams 2004). And thirdly and finally, if employment participation rates are to be raised, the issue is not simply one of deterring undeclared work, 
but rather of moving undeclared work into the declared realm.

For these reasons, calls have been made for governments to transform undeclared work into declared work rather than to simply deter it (European Commission 2003a, 2003b, 2003c and 2007). Indeed, in its second communication on undeclared work the European Commission (2007) explicitly called for member states to pursue policy measures to transform undeclared work into declared work. As Williams (2008) and Williams and Renooy (2009) note, these measures are of three kinds: preventative measures that stop from the outset occurrences of non-compliance; curative measures to help those already working on an undeclared basis to transfer into the declared realm, and commitment measures that foster an allegiance to tax morality. The issue, of course, is whether governments are moving towards this enabling approach based on legitimising undeclared work.

\section{Examining the policy approaches of European governments}

To evaluate the degree to which this European Commission call has been adopted by European national governments, a web-based survey was conducted during 2010 of senior officials responsible for tackling undeclared work in European countries in labour inspectorates, revenue administrations, social security administrations, trade unions, employer organisations and other relevant agencies (e.g. customs, border police, immigration). Of the 499 invitations to participate, 104 responses were received (a 21 percent response rate). In all 31 countries (27 EU member states along with Iceland, Norway and Switzerland), at least one high-ranking representative of the authority who takes the lead on tackling undeclared work was surveyed. The issues covered by this survey included: the characteristics of the current national institutional framework in each country; the existing policy measures used; their perceptions of the importance of each policy measure in the overall approach adopted; their perceptions of its effectiveness at tackling undeclared work; perceived best practices in this field, and the usefulness of various possible options for a European platform to prevent and fight undeclared work.

Secondly, and following this web survey, 24 in-depth semi-structured interviews were held with a selection of these stakeholders. The intention was firstly to pro- vide additional information to fill in any gaps on existing national institutional frameworks, policy measures adopted in different countries and crossborder cooperation following the web survey, and secondly, to seek richer in-depth understanding of the various approaches being adopted and the perceived effectiveness and importance of them. The findings are reported below.

To evaluate whether policy measures have been adopted to transform undeclared work into declared employment, the proportion of countries that used a range of deterrence, preventative, curative and commitment measures to tackle undeclared work in 2010 are reviewed here.

\section{Deterrence measures}

The finding is that in 2010, all 31 countries were continuing to use deterrence measures aimed at stamping out undeclared work, with all seeking to improve detection and 93 percent using penalties and/or sanctions. Examining the percentage of countries using various types of penalties:

- 87 percent used administrative sanctions for purchasers/companies,

- 83 percent imposed administrative sanctions for suppliers/employees,

- 74 percent imposed penal sanctions for purchasers/companies, and

- 53 percent imposed penal sanctions for suppliers/employees.

Analysing the proportion of countries adopting measures to improve detection, meanwhile, the finding is that:

- 100 percent conducted workplace inspections,

- 83 percent used data matching and sharing,

- 74 percent registered workers prior to starting work or on first day of work,

- 65 percent implemented certification of business and/or payments of social contribution and taxes,

- 65 percent used coordinated data sharing across government,

- 65 percent used mandatory IDs in the workplace,

- 61 percent practiced the coordination of operations across government,

- 57 percent coordinated strategy across government, and

- 39 percent used peer-to-peer surveillance (e.g. telephone hotlines). 
Overall, therefore, a wide range of penalties and detection measures were being employed across these 31 European nations.

\section{Preventative measures}

Turning to measures to facilitate the formalisation of undeclared work, the finding is that although such policy measures have been employed to transfer undeclared work into the declared realm, as called for by the European Commission, the range of measures adopted has been relatively narrow. Starting with preventative measures, the finding is that 90 percent of countries adopted one or more preventative policy measure. However, beyond the simplification of compliance, only a limited number of countries have adopted other preventative policy measures. Examining the percentage of countries adopting various preventative measures to stop people and businesses engaging in undeclared work from the outset, the finding is that:

- 87 percent have simplified compliance procedures,

- 65 percent ease transition from unemployment into self-employment,

- 61 percent offer training \& support to business start-ups,

- 61 percent apply direct tax incentives (e.g. exemptions, deductions),

- 61 percent have taken advice on how to formalise,

- 61 percent connect pension schemes to formal labour.

- 52 percent offer micro-finance to business start-ups,

- 48 percent are upwardly revising the minimum wage,

- 48 percent have cut back on regulations,

- 44 percent ease the transition from employment into self-employment,

- 43 percent restrict free movement of (foreign) workers,

- 43 percent introduce technological innovations (e.g. certified cash registers),

- 35 percent apply new categories of work (e.g. for small or mini-jobs),

- 35 percent offer social security incentives,

- 17 percent are introducing supply chain responsibility, and

- 9 percent are downwardly revising the minimum wage.

\section{Curative measures}

It is similarly the case that curative measures that seek to shift undeclared work into the declared realm have not been widely adopted. Just 64 percent of countries use one or more curative measure to tackle undeclared work and again, the range of curative measures used is narrow. Beyond targeted direct tax incentives (e.g. income tax relief/reduction/subsidy schemes), less than one-third of countries have adopted any other curative policy measure. Examining the percentage of countries adopting various type of curative measure, the finding is that:

- 61 percent targeted direct tax incentives at customers of undeclared work,

- 30 percent provided formalisation advice to business,

- 30 percent provided formalisation support services to businesses,

- 26 percent offered service vouchers,

- 22 percent had fact sheets on record-keeping,

- 22 percent offered free advice/training on recordkeeping,

- 17 percent targeted VAT reductions,

- 17 percent had individual-level amnesties for voluntary disclosure,

- 17 percent targeted indirect taxes at customers of undeclared work,

- 13 percent offered free record-keeping software to businesses,

- 13 percent implemented gradual formalisation schemes, and

- 9 percent offered society-wide amnesties.

\section{Commitment measures}

Finally, only 69 percent of the countries have adopted commitment measures and in the countries in which they have been adopted. These have so far mostly involved campaigns targeting various groups involved in undeclared work. Few countries have pursued policy measures to improve either procedural justice or the perceived fairness of the system. Examining the percentage of countries adopting various type of commitment measure, the finding is that:

- 65 percent adopted measures to improve tax/social security/labour law knowledge,

- 61 percent ran campaigns on risks and costs of working undeclared,

- 61 percent ran campaigns to inform users of undeclared work of the risks and costs,

- 57 percent ran campaigns on benefits of formalising their work,

- 52 percent ran campaigns to inform users of the benefits of declared work, 
- 52 percent used normative appeals to people to declare their activities,

- 39 percent ran campaigns to encourage a culture of commitment to declaration,

- 30 percent adopted the commitment rather than compliance approach,

- 26 percent adopted measures to change perceived fairness of the system, and

- 17 percent adopted measures to improve the procedural justice of the system.

\section{Perceived effectiveness of policy measures}

Consequently, deterrence measures remain widely used. The strong intimation is that despite the call for policy measures to transform undeclared work into declared employment, such measures have not been broadly implemented. To explain this, Table 1 reports stakeholders' views on what is the most effective policy instrument for tackling undeclared work. Stakeholders were asked to name the set of policy measures they view as most effective, second most effective and least effective at tackling undeclared work. The finding is that the majority ( 55 percent) see deterrence measures as the most effective means of tackling undeclared work, whilst just 20 percent view preventative measures as the most effective set of measures, followed by 15 percent for curative measures and 10 percent for commitment measures. Stakeholders across Europe, therefore, remain entrenched in a view that deterrence is more effective and a deterrence approach therefore takes precedence over moving undeclared work into the declared realm.

\section{Relative importance of each set of policy measures}

The strong intimation, therefore, is that the deterrence approach is still the most important means of tackling undeclared work. To evaluate this, stakeholders were asked to rank the four different sets of policy measures in terms of which is accorded the most importance to the least importance in their country when tackling undeclared work. Table 2 reports the results. As shown in the table, 57 percent of stakeholders state that deterrence measures are accorded the most importance in their country when tackling undeclared work and just 43 percent deem measures that transform undeclared work into declared employment as the most important, with 19 percent citing preventative measures, 14 percent curative measures and just 10 percent citing commitment measures.

Examining the type of policy measure accorded the least importance, some 84 percent cite those that seek to transform undeclared work into declared employment; only 16 percent cite deterrence measures. The clear message, therefore, is that despite the call by the European Commission to move beyond deterrence, the vast bulk of countries remain entrenched in a deterrence approach and transforming undeclared work into declared employment is neither widely accepted nor adopted.
Table 1

Type of policy measures stakeholders view as most and least effective

\begin{tabular}{|l|c|c|c|}
\hline \% of stakeholders & $\begin{array}{c}\text { Most } \\
\text { effective }\end{array}$ & $\begin{array}{c}\text { 2nd most } \\
\text { effective }\end{array}$ & $\begin{array}{c}\text { Least } \\
\text { effective }\end{array}$ \\
\hline Deterrence measures & 55 & 13 & 12 \\
Preventative measures & 20 & 41 & 13 \\
Curative measures & 15 & 27 & 31 \\
Measures fostering commitment & 10 & 19 & 44 \\
\hline
\end{tabular}

Table 2

Stakeholder opinion of the relative importance accorded to different types of policy measure in their country

\begin{tabular}{|l|c|c|c|}
\hline \% citing & $\begin{array}{c}\text { Most } \\
\text { important }\end{array}$ & $\begin{array}{c}\text { 2nd } \\
\text { important }\end{array}$ & $\begin{array}{c}\text { Least } \\
\text { important }\end{array}$ \\
\hline Deterrence measures & 57 & 17 & 16 \\
Preventative measures & 19 & 46 & 23 \\
Curative measures & 14 & 19 & 32 \\
Commitment measures & 10 & 18 & 29 \\
\hline
\end{tabular}

\section{Conclusions}

In the current period austerity and declining employment participation rates, however, the European Commission has called for a new approach which seeks to transform undeclared work into declared work, not least in order to improve employment participation rates. This paper has evaluated the degree to which this EU call has been adopted by European national governments. Reporting a 2010 survey, the finding is that although European nations have adopted an array of policy measures to facilitate the declaration of undeclared work, deterrence is not only accorded 
the most importance, but is also seen as more effective at tackling undeclared work. The clear lesson, therefore, is that the view that undeclared work needs to be transferred into the declared realm is far from being widely accepted or adopted.

This has important implications. Unless this approach of shifting undeclared work into the declared realm becomes more widely accepted and adopted, then governments will continue not only hinder the promotion of economic inclusion, but will also unintentionally prevent precisely the entrepreneurship and active citizenship that they are so desperately seeking to nurture through their enterprise culture and active citizenship policies through their deterrence approach towards undeclared work. These contradictions can only be resolved by putting greater emphasis on seeking to legitimise undeclared work using preventative, curative and commitment policy measures.

To conclude, this paper for the first time identifies the gap between the European Commission's desire to transfer undeclared work into the declared realm and the dominant approach of European national governments, which still seeks to deter such work rather than transform it into declared work. Action to bridge this gap is therefore needed. If this paper encourages greater discussion of how to encourage such a policy approach amongst national governments, and greater debate across European countries about the unintended consequences for economic inclusion, entrepreneurship and active citizenship of continuing to pursue their deterrence approach, then it will have achieved its objectives.

\section{References}

Allingham, M. and A. Sandmo (1972), "Income Tax Evasion: A Theoretical Analysis", Journal of Public Economics 1, 323-338.

Davis, M. (2006), Planet of Slums, London: Verso.

European Commission (1998), Communication of the Commission on Undeclared Work, http://europa.eu.int/comm/employment_social/ empl_esf/docs/com98-219_en.pdf.

European Commission (2002), Commission Calls on Governments to Do More to Fight the Shadow Economy, Press Release IP/02/339, Brussels.

European Commission (2003a), European Commission Proposes 10 Priorities for Employment Reform, Press Release 0311, Brussels.

European Commission (2003b), Council Decision on Guidelines for the Employment Policies of the Member States, Official Journal of the European Union, 22 July, L.197/13.

European Commission (2003c), Council Resolution on Transforming Undeclared Work into Regular Employment, Official Journal of the European Union, 29 October, C260, http://europa.eu.int/eurlex/en/archive/index.html.

European Commission (2007), Stepping Up the Fight against Undeclared Work, Brussels.
Friedman, E., S. Johnson, D. Kaufmann and P. Zoido (2000), "Dodging the Grabbing Hand: The Determinants of Unofficial Activity in 69 Countries", Journal of Public Economics 76, 459-493.

Hasseldine, J. and Z. Li (1999), "More Tax Evasion Research Required in New Millennium", Crime, Law and Social Change 31 91-104.

Karpuskiene, V. (2007), Undeclared Work, Tax Evasion and Avoidance in Lithuania, Paper presented at Colloquium of the Belgian Federal Service for Social Security on Undeclared Work, Tax Evasion and Service for Social Security
Avoidance, Brussels, June.

Murphy, K. (2005), "Regulating More Effectively: The Relationship between Procedural Justice, Legitimacy and Tax Non-compliance", Journal of Law and Society 32, 562-589.

Neef, R. (2002), "Aspects of the Informal Economy in a Transforming Country: The Case of Romania", International Journal of Urban and Regional Research 26, 299-322.

OECD (2002), Measuring the Non-observed Economy, OECD, Paris.

Persson, A. and H. Malmer (2006), Purchasing and Performing Undeclared Work in Sweden: Part 1: Results from Various Studies, Malmo: Skatteverket.

Richardson, M. and A. Sawyer (2001), "A Taxonomy of the Tax Compliance Literature: Further Findings, Problems and Prospects", Australian Tax Forum 16, 137-320.

Round, J., C.C. Williams and P. Rodgers (2008), "Corruption in the Post-Soviet Workplace: The Experiences of Recent Graduates in Contemporary Ukraine", Work, Employment \& Society 22, 149-166.

Sassen, S. (1997), Informalization in Advanced Market Economies, Discussion Paper 20, Issues in Development, International Labour Office, Geneva.

Schneider, F., A. Buehn and C.E. Monetenegro (2011), "Shadow Economies All over the World: New Estimates for 162 Countries from 1999 to 2007", in: Schneider, F. (ed.), Handbook on the Shadow Economy, Cheltenham: Edward Elgar, 9-77.

Small Business Council (2004), Small Business in the Informal Economy: Making the Transition to the Formal Economy, London.

TNS Infratest, Rockwool Foundation and Regioplan (2006), Feasibility Study on a Direct Survey about Undeclared Work VC/2005/0276, Directorate General of Employment and Social Affairs, European Commission, Brussels.

Williams, C.C. (2004), Cash-in-hand Work: The Underground Sector and Hidden Economy of Favours, Basingstoke: Palgrave Macmillan.

Williams, C.C. (2005), "The Undeclared Sector, Self-employment and Public Policy", International Journal of Entrepreneurial Behaviour and Research 11, 244-257.

Williams, C.C. (2006), The Hidden Enterprise Culture: Entrepreneurship in the Underground Economy, Cheltenham: Edward Elgar.

Williams, C.C. (2007), "Tackling Undeclared Work in Europe: Lessons from a Study of Ukraine", European Journal of Industrial Relations 13, 219-237.

Williams, C.C. (2008), "A Critical Evaluation of Public Policy towards Undeclared Work in the European Union", Journal of European Integration 30, 273-290.

Williams, C.C. and P. Renooy (2009), Measures to Combat Undeclared Work in 27 European Union Member States and Norway, European Foundation for the Improvement of Living and Working Conditions, Dublin.

Williams, C.C. and J. Windebank (2011), "Regional Variations in the Nature of the Shadow Economy: Evidence from a Survey of 27 European Union Member States", in: Schneider, F. (ed.), 27 European Union Member States", in: Schneider, F. (ed.),
Handbook on the Shadow Economy, Cheltenham: Edward Elgar, $177-200$

Woolfson, C. (2007), "Pushing the Envelope: The 'Informalization' of Labour in Post-communist New EU Member States", Work, Employment \& Society 21, 551-564. 